Supplement of Hydrol. Earth Syst. Sci., 21, 533-548, 2017

http://www.hydrol-earth-syst-sci.net/21/533/2017/

doi:10.5194/hess-21-533-2017-supplement

(C) Author(s) 2017. CC Attribution 3.0 License.

(c) (1)

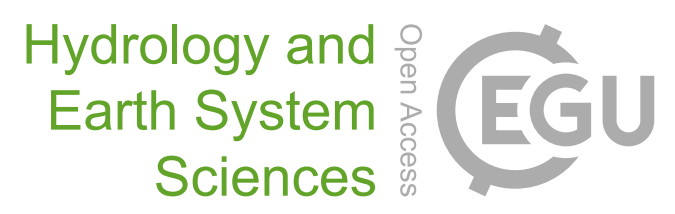

Supplement of

\title{
Response of water vapour D-excess to land-atmosphere interactions in a semi-arid environment
}

Stephen D. Parkes et al.

Correspondence to: Stephen D. Parkes (stephen.parkes@kaust.edu.sa)

The copyright of individual parts of the supplement might differ from the CC-BY 3.0 licence. 


\section{S1. Supplementary materials}

\section{Calibration of in-situ water vapor analysers}

Both Picarro and LGR analysers were calibrated using a custom built calibration unit. Water vapour cross-sensitivity were determined by measuring a single isotopic standard $\left(\delta^{2} \mathrm{H}=-65.6 \%\right.$ o and $\delta^{18} \mathrm{O}=-7.88 \%$ ) at mixing ratios between 4 and $25 \mathrm{mmol}$.mol-1, covering the whole range observed during the campaign. The water vapour cross-sensitivities for $\delta^{2} \mathrm{H}$ and $\mathrm{O}^{18} \mathrm{O}$ from both instruments were non-linear, especially at low mixing ratios. To correct in-situ data for the crosssensitivity, results from the calibration experiments before and after the campaign were composited and a polynomial fit was applied to the data. Using the resulting polynomial equations the in-situ data was corrected for the water vapour cross-sensitivity.

\section{Comparison of in-situ isotopic analysers during field deployment}

As calibration of the two analysers was based upon corrections determined in the lab, and calibration in the field was restricted to irregular drift checks of the Picarro analyser, we periodically set the two analysers to simultaneously sample from the meteorological tower. By comparing the two analysers over this period we could assess the level of accuracy of measurements. Differences between analysers calculated for isotopic measurements for these time periods (shown as 30 minute averages) are shown in figure S1. Due to the large temperature dependence of the LGR, large differences in isotope measurements were observed at night, with the LGR reporting nonsensical values. We therefore restrict chamber measurements and the comparison presented here to daytime periods when the LGR cavity temperature stabilised. The $\mathrm{H}_{2} \mathrm{O}$ concentration for these periods are also shown, indicating the difference between isotopic 
measurements of the analysers does not correlate with the $\mathrm{H}_{2} \mathrm{O}$ concentration and the water vapour cross-sensitivity determined in the lab was correctly characterised and was representative of the whole campaign.
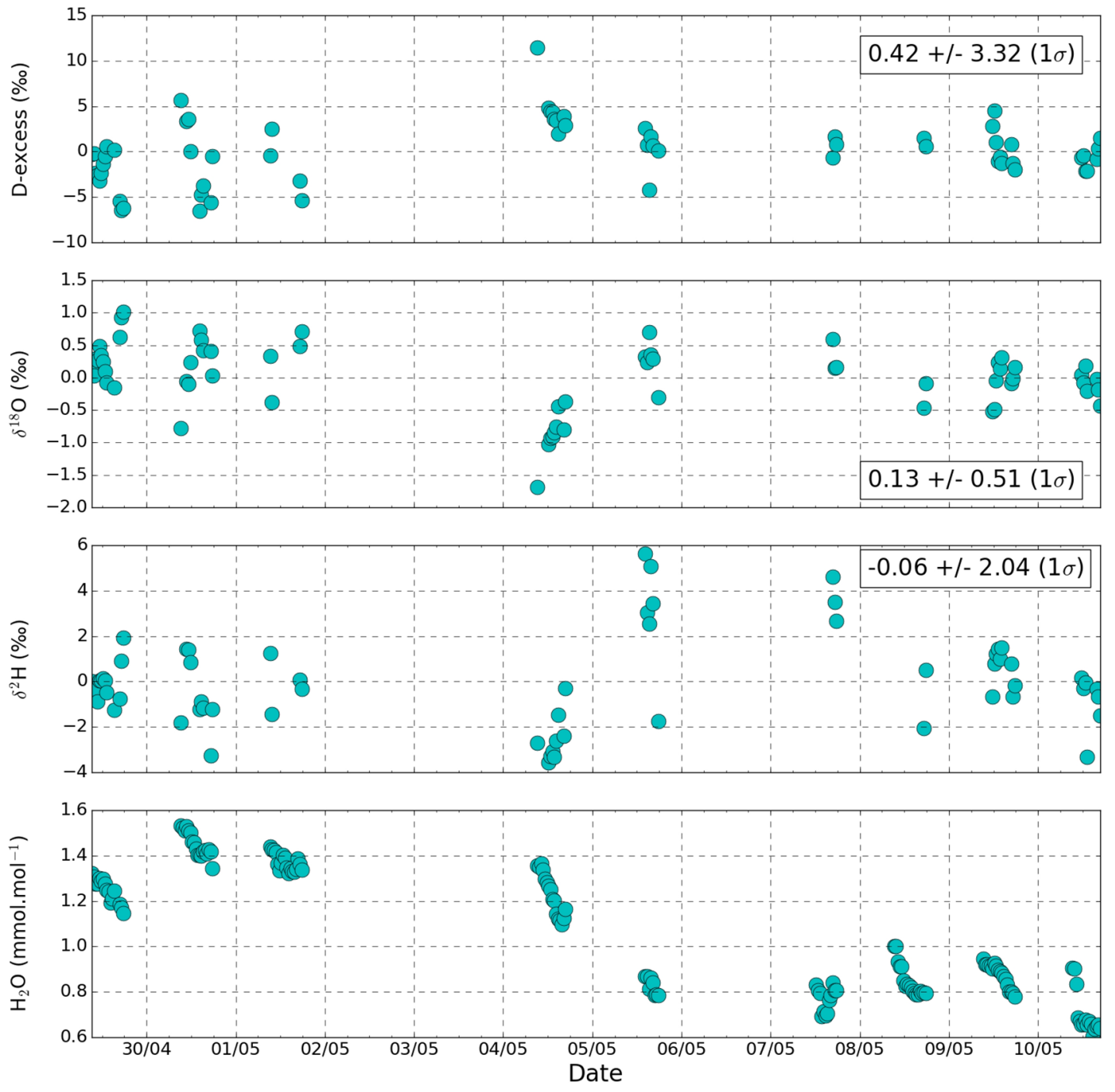


\section{Chamber environment and the isotopic composition of evapotranspiration fluxes}

Modification of the evaporative environment caused by the chamber can lead to biases in the determined isotopic composition. Changes to the temperature at the evaporation site, relative humidity, isotopic composition of the ambient water vapour and the relationship between turbulent transport and molecular diffusion could all influence the isotopic composition of the flux. The meteorological measurements within the chamber provided a means to assess this impact. The temperature increases observed were generally less than $4^{\circ} \mathrm{C}$, but as high as $8^{\circ} \mathrm{C}$ was observed (figure S2). At a temperature of $20^{\circ} \mathrm{C}$ a $4^{\circ} \mathrm{C}$ increase could lead to an increase of 3.5 , 0.3 and $0.7 \%$ increase in the $\delta^{2} \mathrm{H}_{\mathrm{ET}}, \delta^{18} \mathrm{O}_{\mathrm{ET}}$ and $d_{E T}$, respectively. The majority of chamber measurements showed relative humidity increased by less than $10 \%$, but as high as $20 \%$ was observed. Using the Craig and Gordon model and the average conditions observed for the chambers, an increase of $10 \%$ in relative humidity could cause the evaporative fluxes isotopic composition to change by $0.2,0.3$ and $-1.8 \%$ for $\delta^{2} \mathrm{H}_{\mathrm{ET}}, \delta^{18} \mathrm{O}_{\mathrm{ET}}$ and $d_{E T}$, respectively. These estimates of the impact of the chamber environment on the isotopic composition of evaporative fluxes probably represents an upper estimate, as it assumes the chamber environment has an immediate effect on the fluxes. These estimated impacts of increased temperature and relative humidity in the chamber are much smaller the differences between the isotopic composition of ambient vapour and the ET fluxes. 


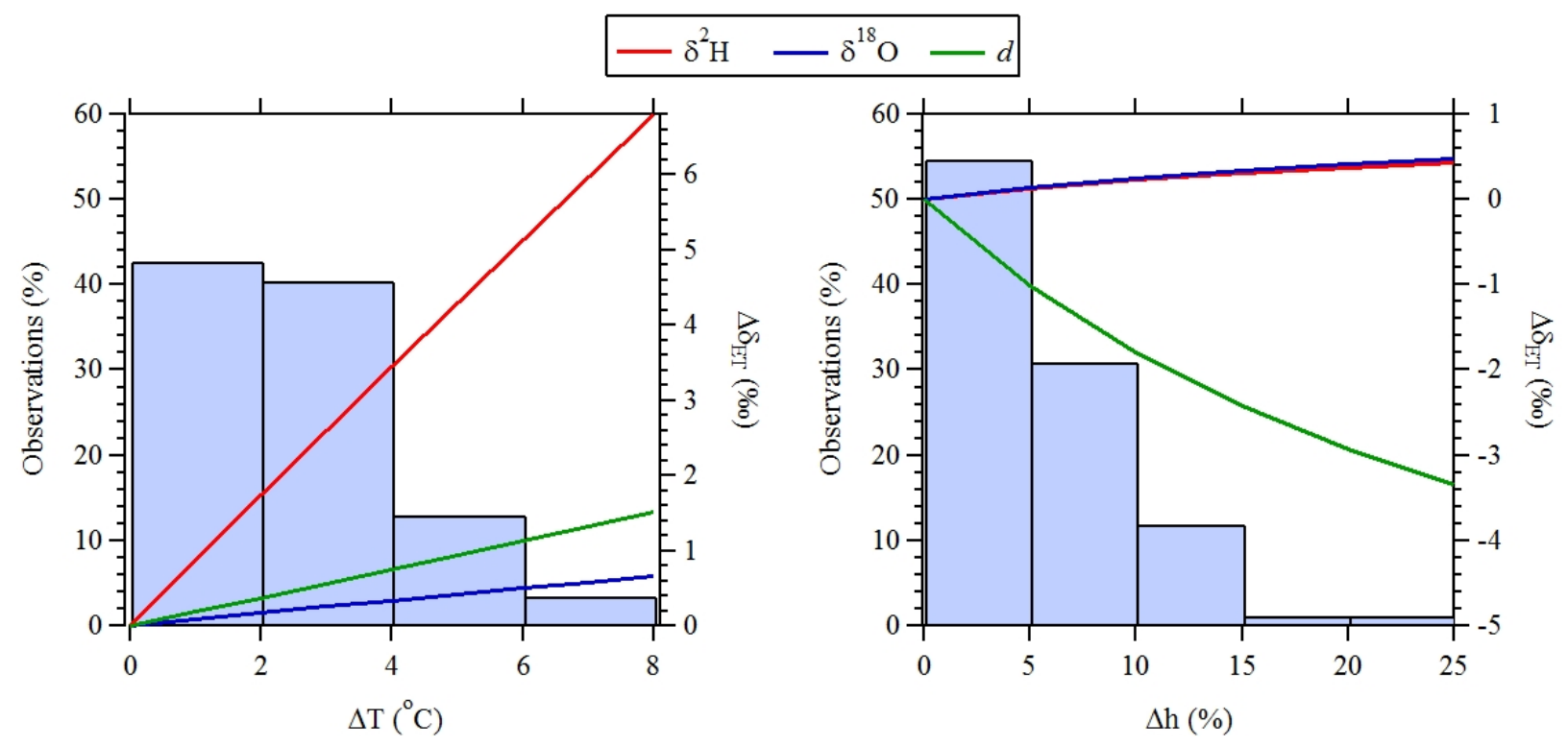

Figure S1: Distribution of the change in evaporation conditions within the chamber for all chamber measurements, including both bare soil and vegetated chambers.
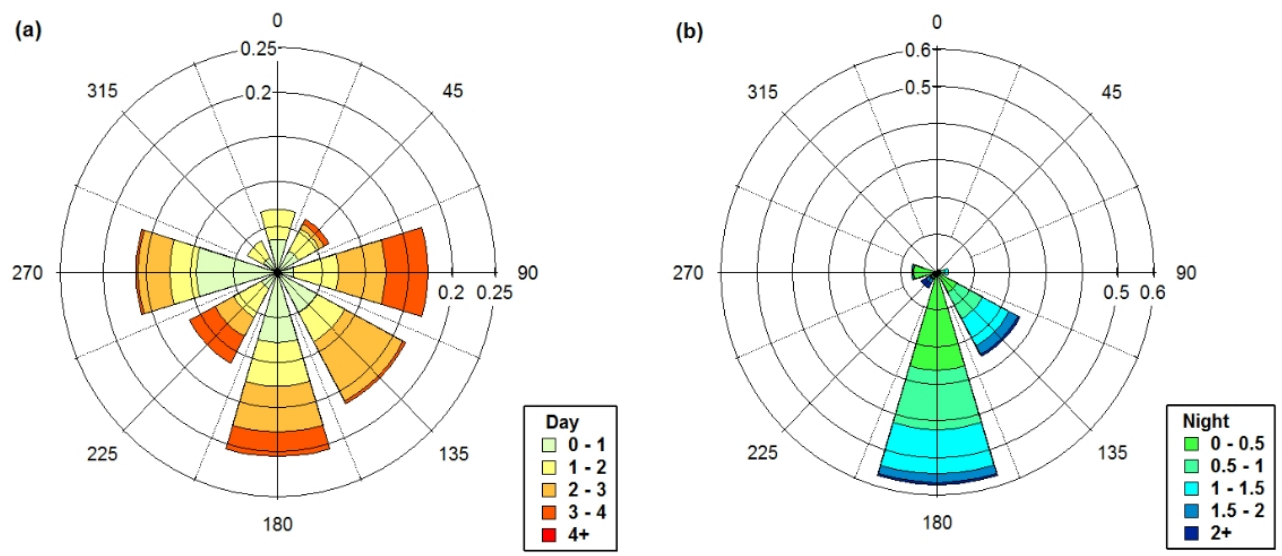

Figure S2: Wind roses determined for the daytime and nocturnal wind observations. 

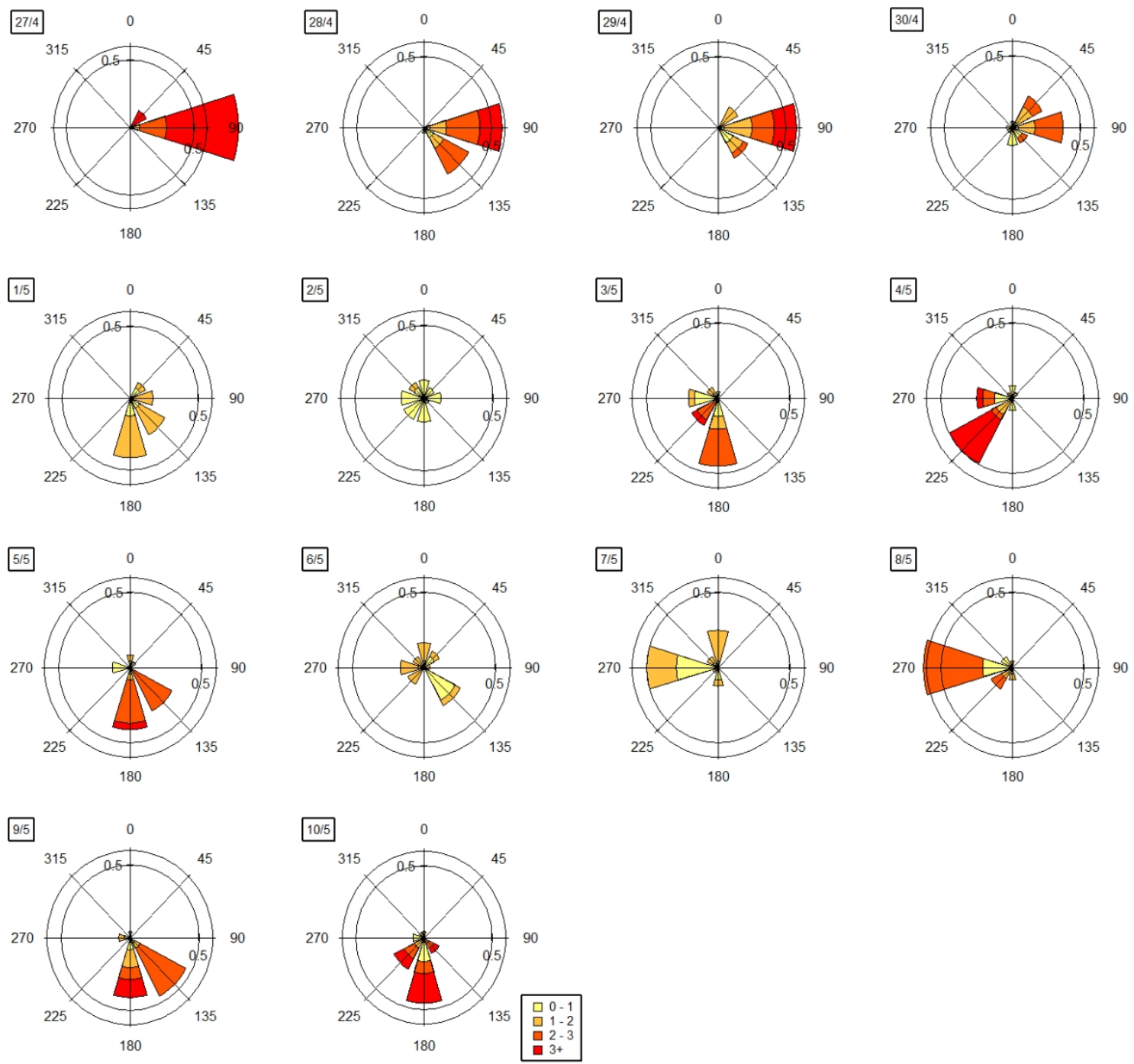

Figure S3: Wind roses determined for the daytime observations on each day of the campaign. Date of the observations are shown on each plot. 